\title{
2015 James Ewing Lecture: The 75-Year History of the Society of Surgical Oncology_Part I: The Traditional Years (1940-1965)
}

\author{
Charles M. Balch, MD' ${ }^{1}$, Daniel G. Coit, $\mathrm{MD}^{2}$, and Russell S. Berman, $\mathrm{MD}^{3}$ \\ ${ }^{1}$ Department of Surgery, University of Texas Southwestern Medical Center, Dallas, TX; ${ }^{2}$ Memorial Sloan Kettering \\ Cancer Center, New York, NY; ${ }^{3}$ Department of Surgery, New York University School of Medicine, New York, NY
}

It is an honor and a privilege for me (CMB) to give the James Ewing lecture and review some historical highlights that have occurred over the past 75 years of the Society of Surgical Oncology (SSO). The Society began as an alumni organization for surgeons trained at Memorial Hospital (itself an important part of surgical oncology history) that evolved into a national and then global society for surgeons treating cancer. We have identified 11 historical highlights, although there are many more that could have been included (Table 1).

There is so much rich history about the heritage of this Society and its leaders that has not been available in the public domain. For this reason, the editors of the Annals of Surgical Oncology have agreed to publish a three-part series in 25-year segments: 1940-1965 ("The Traditional Years"), 1966-1990 ("The Transitional Years"), and 1991-2015 ("The Transformative Years"). Many of the quotations are taken directly from the minutes of the Society's Board meetings through the years. Additional details and background information are available in the electronic supplementary material and on the SSO website.

Electronic supplementary material The online version of this article (doi:10.1245/s10434-015-4837-0) contains supplementary material, which is available to authorized users.

(C) Society of Surgical Oncology 2015

First Received: 11 August 2015;

Published Online: 4 September 2015

C. M. Balch, MD

e-mail: charles.balch@utsouthwestern.edu

\section{DR. JAMES EWING: THE INSPIRATION FOR THE SOCIETY}

Many previous publications have described the inspiring life of Dr. James Ewing (Fig. 1). This extraordinary man was a noted pathologist and director of Memorial Hospital from 1931 to $1939^{1-6}$ Time magazine published an extensive cover article about Dr. Ewing in 1931 and described him as "Mr. Cancer Man", achieving the same legacy while alive as William Osler and Harvey Cushing. In addition to his enormous impact as a pathologist, Dr. Ewing had a visionary influence on the field of surgical oncology, as described by President Edward Scanlon in 1975: "It is James Ewing, more than any other man, who can be said to be the founder of surgical oncology in this century...". 5

During the 1930s, under the leadership of Dr. Ewing as its Director, Memorial Hospital had become the leading free-standing cancer center in the nation, and indeed in the world.

Many of its staff had become icons in American surgery, including Drs. Hayes Martin, Frank Adair, George Pack, Gordon McNeer, and Murray Copeland (Fig. 2). It is important to emphasize that Memorial Hospital had also pioneered the use of radioactive materials for both diagnostic and therapeutic purposes. Indeed, they had acquired a sizeable amount of radium from France and explored many innovative ways to use this material. In the 1930 s and 1940s, surgeons on the Memorial Hospital faculty were trained to use radiation therapy and therefore should be considered as the first surgical oncologists who specialized in using combinations of surgery and radiation therapy in the treatment of their patients. ${ }^{5}$ It is of interest that Dr. George Pack, one of the giants in the field of surgical oncology at that time, was certified in radiation therapy but not in surgery. ${ }^{5}$ 
TABLE 1 Eleven Seminal Events in SSO History

1940: Formation of the James Ewing Society in New York City 1948: First Annual Cancer Symposium of the James Ewing Society

1966: First presidential address by Dr. Glenn H. Leak

1975: James Ewing Society renamed the Society of Surgical Oncology

1983: First surgical oncology fellowship training program approved

1994: Launch of the SSO journal Annals of Surgical Oncology

2003: First Breast Oncology Fellowship training program approved

2010: First 'Best of SSO' presented by the Mexican Oncology Society in Cancun

2011: First SSO Fellows Institute program in Cincinnati, OH

2011: American Board of Surgery approves surgical oncology subspecialty certification

2012: SSO administration moves to self-management

SSO Society of Surgical Oncology

It is interesting that every surgeon practicing at Memorial Hospital at that time was also trained as a radiation oncologist. This may explain swhy many of their first meetings were held during the annual meeting of the American Radium Society. ${ }^{1}$ Dr. William Guiss, in his 1976 presidential address, stated: "I began my training as an oncologic surgeon 38 years ago. At that time [1938], the oncologic surgeon was full time within his field and handled the total aspects of cancer therapy. When I helped open the front doors of the new Memorial Hospital on 68th Street in 1939, each of the oncologic surgical specialists was in charge of all radiation to his patients as well as surgical management and follow-up... there was no radiation therapist in the Department of Radiation. There were two excellent radiologic physicists, Dr. Failla and Dr. Quimby, who acted as very sophisticated consultants... The word "cancer" was absolutely forbidden in any conversations with patients and their families, and the word "oncology" was essentially unknown... What better descriptive term could have been used for any $100 \%$ specialist in any aspect of cancer treatment or study and yet it was forbidden and rejected at the time". ${ }^{7}$

\section{THE FOUNDING 5: THE VISION FOR THE SOCIETY}

In November 1939, five surgeons, namely Drs Al Hocker, John Blady, Sam Binkley, John Wirth, and William MacComb (Fig. 3), met over lunch at the old Memorial Hospital on Central Park West in New York City to plan for a new association for staff, alumni, and trainees of the Memorial Hospital Surgery Department. These individuals created the

\footnotetext{
${ }^{1}$ Later, in 1971, the American Radium Society and the James Ewing Society formally discussed merging the two Societies into an 'American College of Cancer', which was the theme of the presidential address by Dr. Arthur G. James. ${ }^{10}$
}

first vision for the Society and laid out a draft constitution and bylaws that were formalized a year later. They took the initiative to organize the first meeting the following year. Of these five founding organizers, Dr. MacComb was clearly the visionary of this group (Sidebar I).

\section{0: FIRST MEETING OF THE JAMES EWING SOCIETY}

The first meeting of the James Ewing Society was held on 10 June 1940. Nineteen Memorial Hospital alumni plus five current fellows met over lunch at the Lexington Hotel $^{2}$ in New York City during the annual meetings of the American Radium Society and the American Medical Association. Those attending this historic luncheon meeting agreed to form an alumni society. Dr. John Spies suggested the new association should be named 'The James Ewing Society' and William MacComb was named as the first president (Fig. 4).

The next day, Dr. MacComb asked Dr. Ewing for permission to use his name "as a tribute to your leadership and we hope that the efforts of the Alumni thus united will bring honor to you". Dr. Ewing readily agreed and stated he was sure the society "would have a notable future". In November 1940, the new president, William MacComb, appointed a committee to craft the formal constitution and bylaws based on the draft that had been developed a year before by the founding five. The committee comprised of Drs Alfred Hocker, Gordon McNeer, John Wirth, John Blady, and Sam Binkley (Chair).

\section{1: THE SECOND MEETING OF THE JAMES EWING SOCIETY}

The Ewing society met for a second time in Cleveland, OH, in June 1941 during the American Radium Society's Annual Meeting. The constitution and bylaws were approved, and listed the three primary reasons to establish this society: (1) to perpetuate the original ideas of Dr. James Ewing upon which the Fellowship was founded, namely, training in the diagnosis and treatment of cancer; (2) to seek to gain recognition of "cancer as a specialty" by the medical profession; and (3) to strengthen the bonds of friendship among the members. Voting membership was limited to "the regularly selected clinical fellows of Memorial Hospital who have successfully served and completed a three year fellowship...". ${ }^{8}$ Dr. William MacComb was elected as president for a second year.

Those present wanted to have Dr. Ewing come to the next meeting in June 1942 but unfortunately he died of

\footnotetext{
2 The lunch arrangements were organized by Dr. Hocker's wife, Mrs Margaret Hocker.
} 


\section{a}

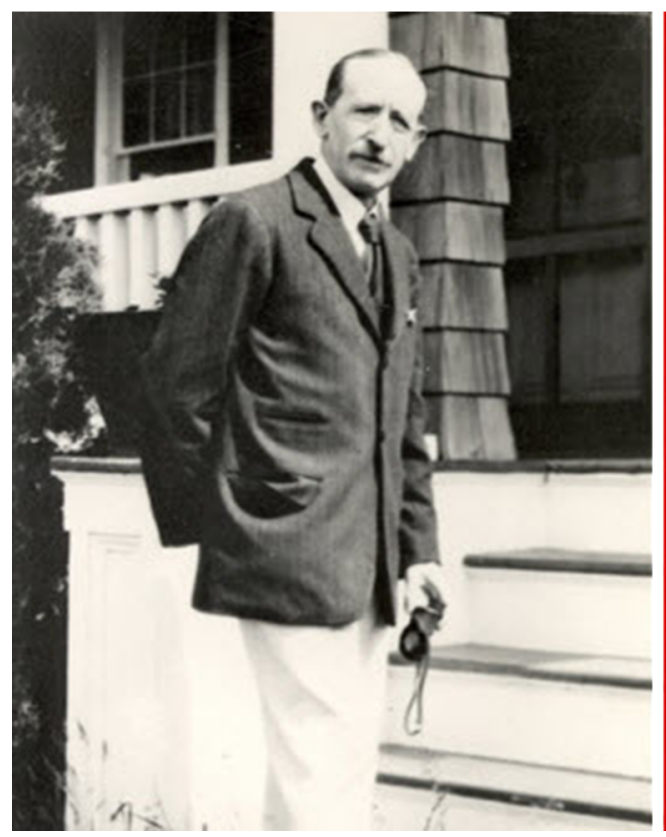

b

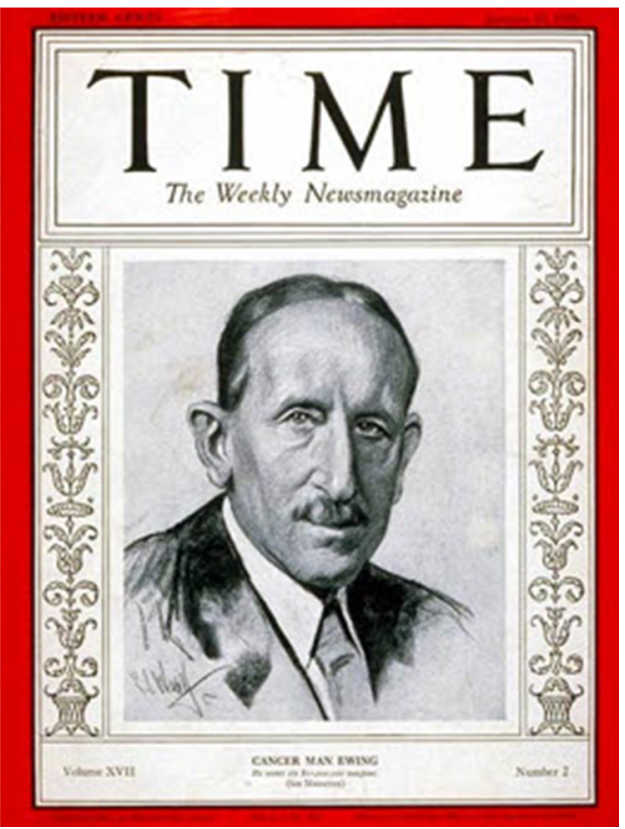

FIG. 1 a Dr. James Ewing: Director of Memorial Hospital (1931-1939) and noted pathologist (courtesy of the MSKCC Archives). b Time Magazine cover article published on 12 January 1931 describing Dr. Ewing as "Mr Cancer Man"

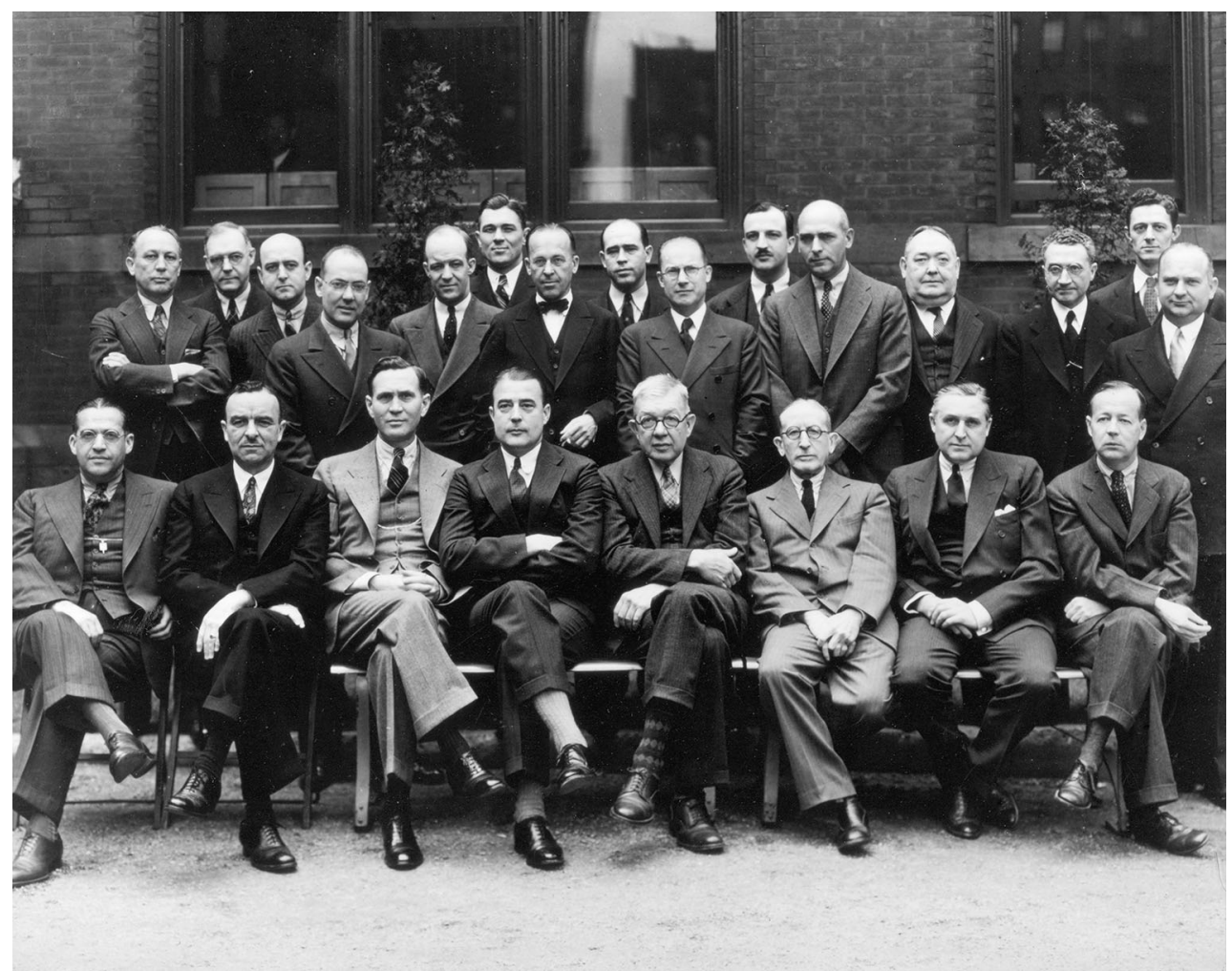

FIG. 2 Attending staff of the Memorial Hospital of New York (1938). Seated Norman Treves, George Ernest Binkley, Hayes Elmer Martin, William Bradley Coley, Benjamin Stockwell Barringer, James Ewing, Frank Earl Adair, and Fred Waldorf Stewart. Standing Ralph Eugene Herendeen, biologist Halsey Joseph Bagg, George Thomas Pack, William Spencer MacComb, Gordon Palmer McNeer,
Alfred Franklin Hocker, George Hall Hyslop, Joseph Helms Farrow, Archie Leigh Dean, Gray Huntington Twombly, Lloyd Freeman Craver, superintendent Mr. George Holmes, physicist Gioacchino Failla, Edgar Leonard Frazell, and Frank Raymond Smith (courtesy of the MSKCC Archives) 

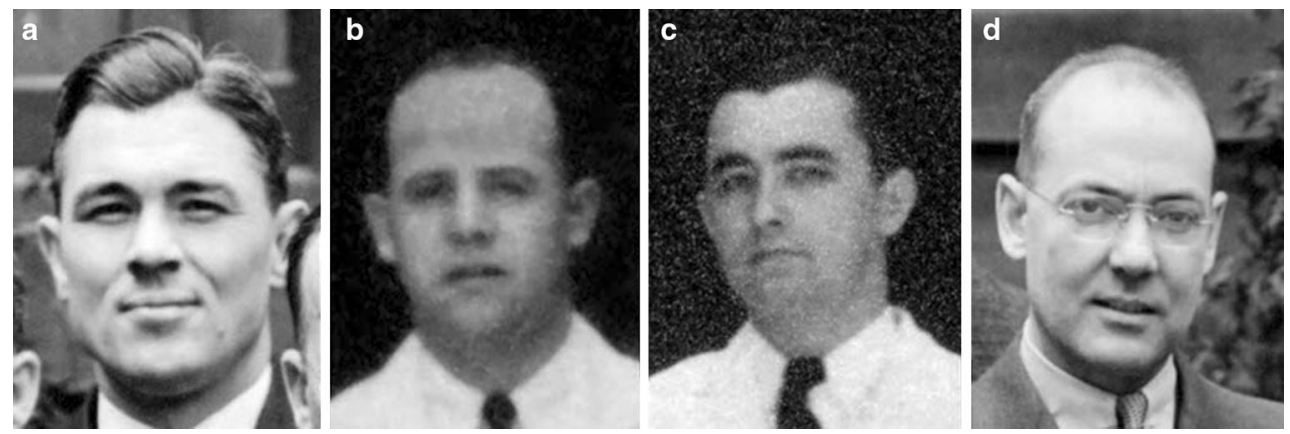

FIG. 3 Founding surgeons of the James Ewing Society. a Al Hocker; b John Blady; c Sam Binkley; d William MacComb. Not shown, John Wirth

metastatic bladder cancer in May that year and was never able to attend a meeting of the Society that carried his name for the next 35 years.

\section{2: THE THIRD MEETING OF THE JAMES EWING SOCIETY IN THE CONTEXT OF WORLD WAR II}

To put the activities of this fledgling society in context, the United States was fully engaged in World War II at this time. In fact, the Battle of Midway occurred during the week of the Society's third meeting in June 1942.

Therefore, it should be no surprise that only ten members were present for a lunch at Haddon Hall in Atlantic City on 9 June 1942. Dr. George Sharp was elected president, Joseph Farrow as Vice-President, and Sam Binkley as Secretary. The annual dues were raised from $\$ 5$ to $\$ 10$. The minutes of the meeting concluded with: "This was the last meeting of the James Ewing Society until after the war". Hence, Dr. Sharp is listed in our records as President for these 5 years until the Society met again in 1947 (Fig. 4).

\section{7: THE SOCIETY STARTS UP AGAIN}

After an interim of 5 years, the Society met over lunch at the Haddon Hall Hotel in Atlantic City on 10 June 1947. Eighteen members attended. Dr. John V. Blady was elected President, Edgar Frazell as Vice-President, and William MacComb as Secretary and Treasurer. The minutes read: "It was the consensus that the James Ewing Society make every effort in the future to help in the establishment of a Board of Oncology. Dr.Whipple ${ }^{3}$ is to be consulted and

\footnotetext{
${ }^{3}$ Dr. Whipple was appointed as Clinical Director of Memorial Hospital after his retirement as Chair of Surgery at Columbia University College of Physicians and Surgeons in order to make Memorial 'more academic' and to recruit surgical residents from university training programs.
}

asked to advise and participate in this movement". A committee was appointed to study this approach.

Those attending the Ewing meeting, including Dr. Blady, suggested "that the James Ewing Society engage actively as a scientific organization and that the Society initiate scientific programs for its Fellows and guests on an annual basis". A new Constitution was changed so that "membership should not be limited to Memorial alumni", but that the total membership should be capped at 250 voting members. The minutes stated that the purpose of the Society was to be national in scope and the purpose of the Society was restated simply "to further the knowledge of cancer". 2,6

\section{8: THE FIRST ANNUAL CANCER SYMPOSIUM OF THE JAMES EWING SOCIETY}

The first Annual Cancer Symposium was held in 1948 at the new Memorial Hospital in its present location on 68th Street in New York City (Fig. 5). During the day and a half meeting, scientific sessions on chemotherapy and radioactive isotopes were held, as well as clinic and laboratory demonstrations and an operative clinic (Fig. 5). Dr. Edgar Frazell was elected as president (Fig. 4). Standing committees were established as Membership, Program, Local Arrangements, Constitution and Bylaws, Nominating, and Audit.

That evening at the Society's dinner, the first James Ewing Lecture was given by Dr. Edith Quimby. After her lecture, she was made the first honorary member of the James Ewing Society (Sidebar II).

\section{GATHERING MOMENTUM AND GROWTH IN THE 1950S}

The Annual Cancer Symposium continued to be a growing success. In the early 1950s, 16-22 papers were presented, and the scientific program had grown to 30 papers by the end of the decade. The annual James Ewing 

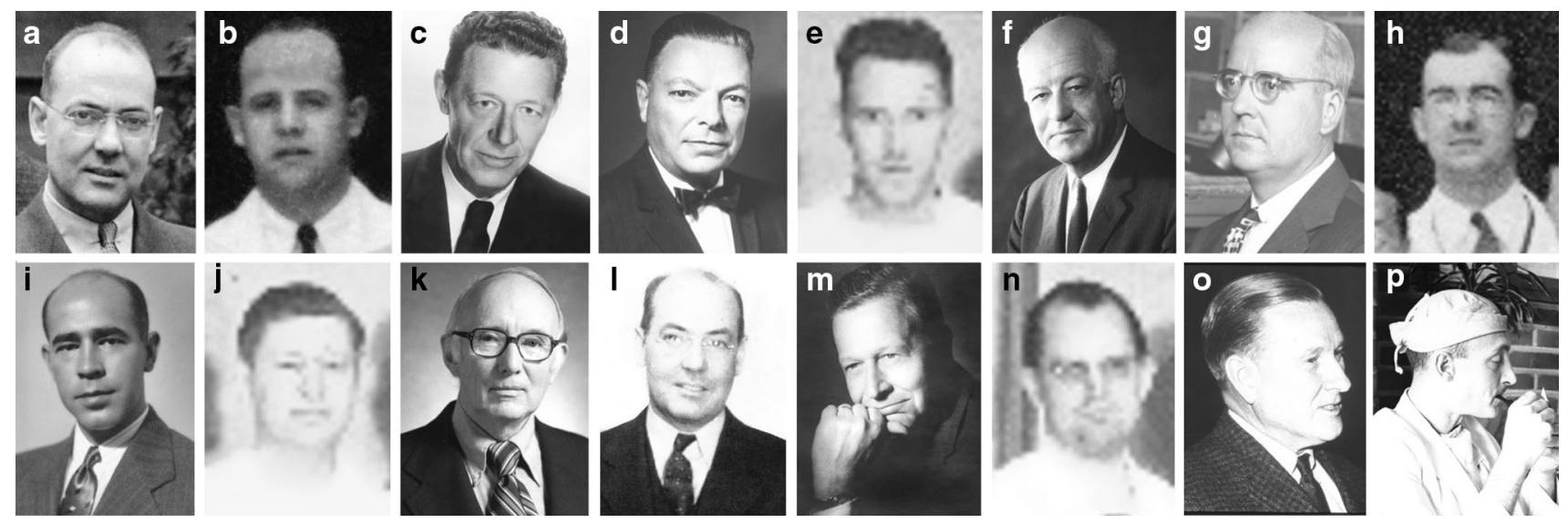

1958; j Ralph R. Braund, MD, 1958-1959; k John L. Pool, MD, 1959-1960; l William S. MacComb, MD, 1960-1961; m Maus W. Stearns Jr, MD, 1961-1962; n Calvin T. Klopp, MD, 1962-1963; o Ashbel C. Williams, MD, 1963-1964; p Lemuel Bowden, MD, 19641965. Not shown: George Sharp, MD, 1942-1947; Thomas J. Anglem, MD, 1951-1952; and Robert Brown, MD, 1952-1953

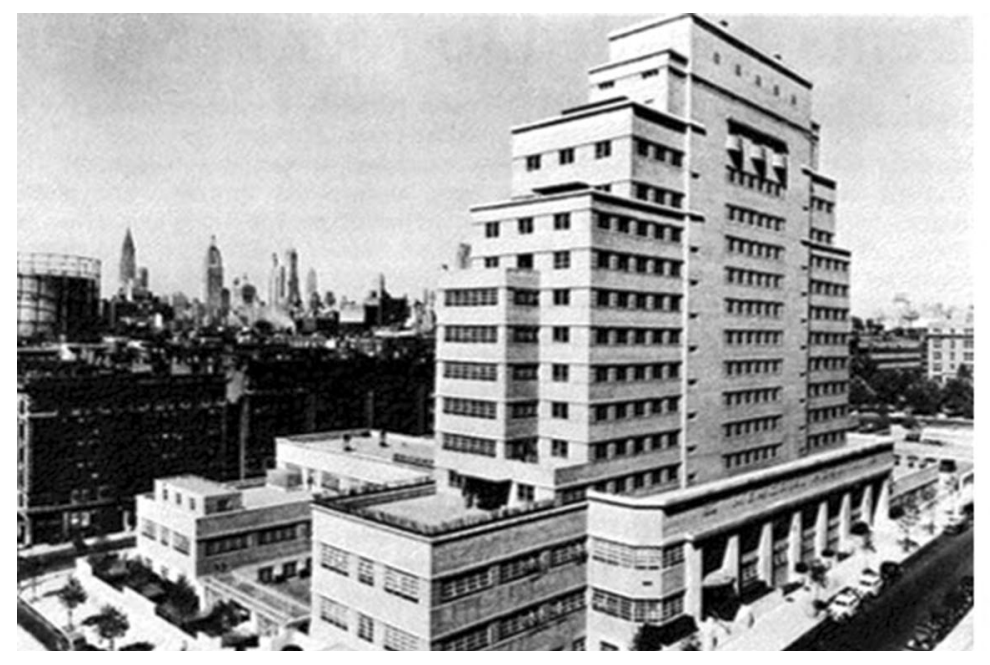

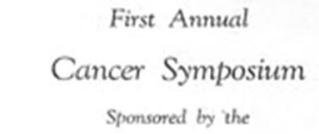

The James Ewing Society

efto

January $16-17,1948$

Memorial Cancer Center New York 2t, New York

FIG. 5 Photo of Memorial Hospital, 1947, and first Annual Cancer Symposium flyer (courtesy of the MSKCC Archives)

Lecture was to be delivered by a leader in either the surgical or oncology fields, and there were panel discussions about multidisciplinary cancer management. Attendance continued to grow and the Ninth Annual Cancer Symposium in April 1956 set an attendance record of 357 attendees (128 members), and 33 new members were elected. The finances of the Society were also in good shape. The minutes of the 1952 meeting thus reported that the Ewing Society had a cash balance of $\$ 1200$, and this "caused considerable applause by the members".

In 1955, a new classification of members was adopted as 'Corresponding Members' to provide for doctors in foreign countries. A medallion was commissioned in the likeness of Dr. James Ewing to be presented each year to the person delivering the James Ewing Lecture.

\section{THE EARLY 1960S}

At the Thirteenth Annual Cancer Symposium in 1960, there were pre-symposium sessions dealing with chemotherapy, radiation therapy, urology, and clinical physiology. Twenty-seven papers were presented at the symposium and the James Ewing Lecture ("The Clinical Aspects of Cancer Susceptibility and Cancer Immunity") was delivered by Dr. George T. Pack. Overall, 114 members attended the business meeting, the largest attendance to date. The annual dues were raised to $\$ 15$. Donations were made to establish the Lucy Wortham James Award and Lecture (\$500) for an individual who had done outstanding laboratory research, and the James Douglas Award for Clinical Research. 
At the 1961 meeting, the first Lucy Wortham James Award was given to Dr. Hayes Martin, and the James Douglas Award was given to Dr. Georgios Papanicolauo. Active membership of the James Ewing Society was now 244 and was rapidly approaching its constitutional limit of 250 members. Qualification for membership was tightened using the following criteria: (1) certification by specialty board; (2) at least two publications in the field of cancer; (3) evidence of formal identification with the field of cancer (e.g., director of a tumor clinic or program, cancer co-coordinator in a teaching institution, or membership in a national or local endeavor of the American Cancer Society); and (4) completion of formal training of at least 2 years prior to application for membership.

The Fifteenth Annual Cancer Symposium was held in Washington, DC, at the Mayflower Hotel in April 1962. Dr. Shields Warren delivered the James Ewing Lecture entitled "Leukemia, Sarcoma, and Radioactivity". The pre-symposium sessions were given at the National Institutes of Health, and were moderated by Dr. Lewis Thomas. There was over $\$ 5000$ in the treasury, and the Society's first Resident Award was given to Dr. Edward D. McLaughlin.

Dr. Glenn H. Leak was elected as President in 1965. Dr. Robert Schweitzer, then a member of the Executive Council, persuaded Dr. Leak to give the first presidential address, as we will present in part II of this series on the 75 -year history of the SSO.,9

ACKNOWLEDGMENT The authors thank Ms. Karen Hurley and Kathy Sampson at the SSO headquarters office for their assistance in gathering materials, Drs. Walter Lawrence and Blake Cady for reviewing the manuscript, and Deborah Whippen for editorial assistance. We also thank Ms Katherine Brennan at the MSKCC Archives, Rockefeller Archives Center, for her assistance in obtaining some of the original minutes of the James Ewing Society, as well as photos. These documents were located in Record Group 520, James Ewing Society Papers.

\section{SIDEBAR I: WILLIAM SPENCER MACCOMB, THE "FATHER" OF THE SSO, (1900-1988)}

Dr. MacComb was one of 'the founding five' Memorial surgeons who started the James Ewing Society. Of these five founding organizers, Dr. MacComb was clearly the visionary of this group, and his leadership of the Society continued in many capacities over the next two decades. $\mathrm{He}$ was elected as the first and second President of the James Ewing Society from 1940 to 1942. In addition, he was elected to the Executive Council when it first formed in 1948 and served in this capacity for the next 14 years. He was also elected as President for a third time in 1960. No other person in the history of the SSO was president for multiple terms and also one of the founding leaders. For these reasons, it would be appropriate, in our view, to state that William MacComb was 'the Father' of the SSO (founded as the James Ewing Society). Dr. MacComb was also president of the American Radium Society in 1950 and president of the American Society of Head and Neck Surgeons (ASHNS) in 1969. He was also honored by giving the inaugural ASHNS Hayes Martin Lecture in 1972.

Dr. MacComb was a pioneer in surgical oncology, having been certified in both surgery and radiation therapy, which he combined in pioneering multimodality treatment approaches to head and neck cancers. He trained and worked for many years under Dr. Hayes Martin at Memorial Hospital in New York, who was the Chief of Head and Neck Surgery from 1932 until his retirement in 1957. Dr. Martin, a founding member of the American Board of Surgery, the American Board of Radiology, and the American Board of Plastic Surgery, believed that "the physician undertaking the treatment of patients with cancer of the head and neck should be prepared and qualified to treat any phase of the disease and that he must always be responsible for all types of therapy, no matter what other specialists might be consulted". ${ }^{11}$ In 1959, Dr. MacComb moved to MD Anderson Cancer Center in Houston in 1952 as the first Chief of Head and Neck Surgery. Cross-trained in radiation therapy and head and neck surgery, Dr. MacComb worked closely with Dr. Gilbert Fletcher, then Chief of Radiation Therapy at MD Anderson Cancer Center, in the multidisciplinary management of head and neck cancers. In the 1960s, they co-authored two seminal books that, for decades, became the standard textbooks on the subject, i.e., Cancer of the Head and Neck by Drs. MacComb and Fletcher, and Radiation Therapy in the Management of Cancers of the Oral Cavity and Orophar$y n x$ by Drs. Fletcher and MacComb.

Dr. MacComb and Dr. Edith Quimby (see Sidebar II) also worked closely together early in their careers, both at the Memorial Hospital and also on the Research and Standardization Committee of the American Radium Society in the early 1940s.
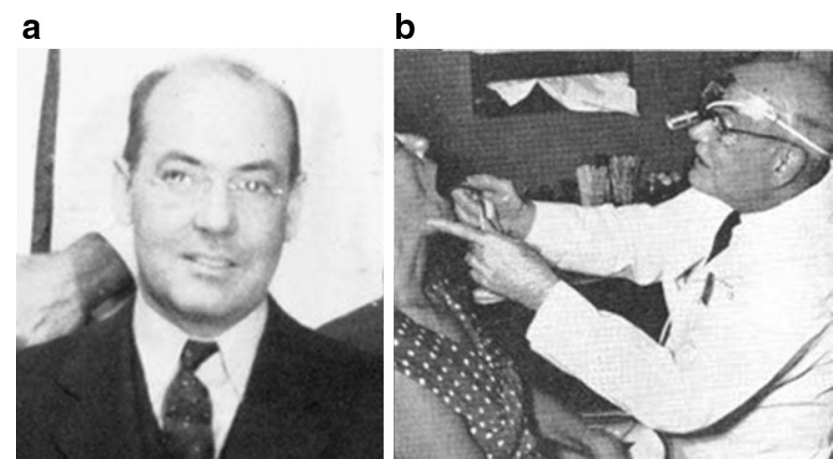

(a) Dr. William S. MacComb, Staff Surgeon of Head and Neck Surgery at Memorial Hospital, New York, circa 1940 (photo courtesy 
of Memorial Sloan Kettering Cancer Centre (MSKCC) Archives), and (b) as the first Chief of Nead and Neck Surgery, MD Anderson Cancer Center (1952-1967).

\section{SIDEBAR II: EDITH HINKLEY QUIMBY, FIRST JAMES EWING LECTURER (1891-1982)}

Edith Quimby gave the first James Ewing Lecture entitled "The History of Cancer Research" on 15 January 1948 in New York City. After her lecture, she was made the first honorary member of the James Ewing Society. She had a vital role in multimodality cancer management of surgical patients at Memorial Hospital, since the surgeons directed all radiation therapy during the 1930s and early 1940s, and Dr. Quimby provided the radiation dosimetry (there were no radiation oncologists at that time).

Dr. Quimby was a pioneer in the field of radiation physics. Working with Dr. Gioacchino Failla at Memorial Hospital, her research determined safe doses of radiation from radiation and radioisotopes. In the 1930s and 1940s, Dr. Quimby helped develop the first therapeutic applications for X-rays, radium, and radioactive isotopes at Memorial Hospital. Very early on, she saw the potential for increased diagnostic and therapeutic use of atomic energy in medicine through radioactive isotopes. She helped develop diagnostic and therapeutic applications for X-rays, radium, and radioactive isotopes when the science of radiology was still in its infancy. Her seminal research measured the penetration of radiation, enabling physicians to use the therapeutic dose needed with the fewest side effects. Indeed, she is considered a founder of the science of radiation physics and nuclear medicine, and provided the first practical guidelines for effective dosage levels using radiation therapy. In 1941, she became an Assistant Professor of Radiology at Cornell University Medical College, and later moved to Columbia University where she was a full Professor until she retired in 1960.

In 1940, the American Radium Society gave her the Janeway Medal, the first woman to receive this prestigious award; she was later elected as the first woman president of the American Radium Society in 1954. She was awarded Gold Medals from the Radiological Society of North America in 1941 and from the American College of Radiology in 1963.
In addition to her research and clinical activities as a radiation physicist, Dr Quimby also worked on the Manhattan project (which developed the atom bomb). She also worked for the Atomic Energy Commission, acted as a consultant on radiation therapy to the United States Veterans Administration, and served as an examiner for the American Board of Radiology. a

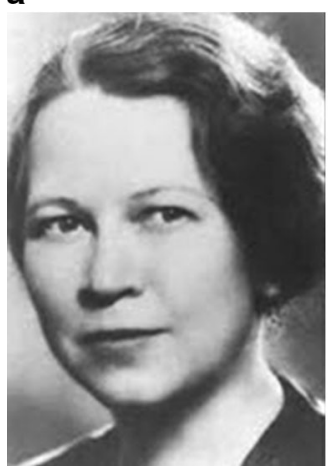

b

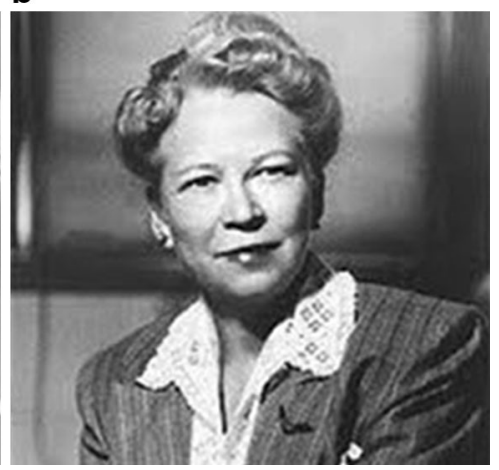

Edith Hinkley Quimby (a) while at Memorial Hospital in the1930s, and (b) as a Professor in Radiology at Columbia College of Physicians and Surgeons in 1950.

\section{REFERENCES}

1. Leffall LD, James Ewing, MD. Contemporary oncologist exemplar. The James Ewing Lecture. Arch Surg. 1987;122:1240-43.

2. Lawrence W. Some problems with clinical trials. James Ewing Lecture. Arch Surg. 1991;126:370-8.

3. Del Regato JH. A biography of the late James Ewing. Int J Radiat Oncol Biol Phys. 1977;2:185-98.

4. Robbins GF. James Ewing: the man. The James Ewing Lecture. Clin Bull. 1978;8:1-4.

5. Scanlon EF. The evolution of surgical oncology. Presidential address: James Ewing Society, New Orleans, 1975. Cancer. 1976;37:58-61.

6. Wilkins SA. The James Ewing Society 1940-1969. Presidential address. Cancer. 1970;25:322.

7. Guiss LW. The surgical oncologist. Cancer. 1977;39:419.

8. Schweitzer RJ. Surgical oncology: the role in cancer control today. Cancer. 1975;35:592-5.

9. Balch CM, Coit D, Berman RS. The 75-year history of the Society of Surgical Oncology. Part II: The transitional years (1966-1990). Ann Surg Oncol. 2015 (in press).

10. James AG. College of Cancer. Cancer. 1971;28:1138-41.

11. MacComb WS. Future of the head and neck cancer surgeon. Am J Surg. 1969;118:651-3. 